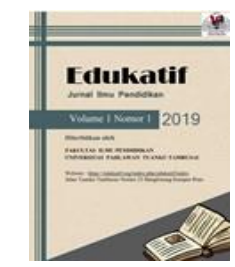

\title{
PENGGUNAAN MEDIA LAGU DALAM PEMBELAJARAN TEMATIK DI SEKOLAH DASAR
}

\author{
Eliza Nola Dwi Putri ${ }^{1}$, Desyandari ${ }^{2}$ \\ Universitas Negeri Padang,Sumatera Barat, Indonesia1,2 \\ Email : noladwiputri1234@gmail.com ${ }^{1}, \underline{\text { desyandri@fip.unp.ac.id }}^{2}$
}

\begin{abstract}
Abstrak
Media merupakan suatu alat bantu yang digunakan oleh guru untuk mencapai keberhasilakan tujuan pembelajaran. Salagu media yang dapat digunakan oleh guru yaitu berupa media audio atau Lagu adalah suatu kesatuan musik yang terdiri dari susunan beberapa nada yang berurutan. Pada setiap lagu ditentukan dengan panjang pendek, tinggi rendahnya nada. Pada lagu terdapat irama yang memberikan corak tertentu pada lagu. Melalui media lagu atau musik siswa dapat berlatih Bahasa pada saat bernyanyi. Dengan menggunakan lagu dengan Bahasa yang sederhana pada pembelajaran tematik akan membantu siswa untuk memahami materi dengan mudah. Selain itu akan meningatkan kreativitas siswa dibidang seni musik. Oleh sebab itu penulis tertarik mengkaji penggunaan media lagu dalam pembelajaran tematik di sekolah dasar.
\end{abstract}

Kata Kunci : Media, Lagu, Pembelaran, Tematik

\begin{abstract}
Media is a tool used by the teacher to achieve the success of learning objectives. Salagu media that can be used by the teacher consists of audio media or song is a combination of music that consists of a sequence of several consecutive tones. In each song is determined by the short length, high and low tones. In the song There is a rhythm that gives a certain style to the song. Through song or music media students can practice language while singing. Using songs with simple language on thematic learning will help students to understand the material easily. In addition it will remind students of creativity in the field of music art. Therefore the author is interested in studying the use of song media in thematic learning in elementary schools.
\end{abstract}

Keywords: Media, Song, Engagement, Thematic

@Edukatif: Jurnal Ilmu Pendidikan FIP UPTT 2019

$\triangle$ Corresponding author :

Address :-

Email :-

ISSN 2656-8063 (Media Cetak)

Phone : - 


\section{PENDAHULUAN}

Kurikulum 2013 menuntut pendidikan sekolah dasar (SD) untuk menggunakan pembelajaran tematik terpadu. Pembelajaran tematik merupakan penggabungan beberapa mata pelajaran yang dikaitkan dalam satu tema dimana akan disampaikan kepada murid dalam satu rangkaian materi. Kaitan konseptual antar mata pelajaran yang akan dipelajari akan membentuk skema, sehingga siswa akan memperoleh keutuhan dan kebulatan pengetahuan. pembeajaran tematik adalah pembelajaran yang berisi suatu pokok bahasan yang dikaitkan dengan pokok bahasan lain didalam satu bidang maupun lebih dan dengan pengalaman siswa. Sepeti pada materi yang diajarkan guru, mengkaitkan satu tema dengan beberpa bahasan dari berbagaii bidang sebagai tujuan pembelajaran (Subroto dala Kadir dan Hanun: 2014). Pembelajaran tematik di SD/MI akan sangat membantu siswa, karena sesuai dengan tahap perkembangan siswa yang masih melihat segala sesuatu sebagai satu keutuhan dan saling berkaitan. Dalam kontes ini siswa Sekolah Dasar dituntut untuk aktif dalam memusatkan perhatian dalam suatu tema tertentu. Karakteristik pembelajaran tematik adalah sebagai berikut (1) anak didik sebagai pusat pembelajaran; (2) memberi pengalaman langsung; (3) menghilangkan batas pemisah antar mata pelajaran; (4) fleksibel; (5) hasil pembelajaran sesuai dengan minat dan kebutuhan anak didik; (6) menggunakan prinsip pakem (pembelajaran aktif, efektif, dan menyenangkan); (7) holistic; (8) bermakna (Azimah :2018).

Menurut Djamarah (2006 : 121) media sebagai alat bantu dalam proses belajar mengajar adalah suatu kenyataan yang tidak dapat dipungkiri. Karena memang gurulah yang menghendakinya untuk membantu tugas guru dalam menyampaikan pesan-pesan dari bahan pelajaran yang diberikan oleh guru kepada anak didik. Guru sadar bahwa tanpa media, maka bahan pelajaran sukar untuk dicerna dan dipahami oleh setiap anak didik, terutama bahan pelajaran yang rumit atau kompleks. Penggunaan media dalam proses pembelajaran dapat mempermudah guru menyampaikan suatu informasi. Oleh karena itu untuk menciptakan suasana belajar aktif, kreatif, efektif dan menyenangkan guru dituntut untuk lebih kreatif dan inovatif dalam merancang dan menggunakan media pembelajaran. (Maghfiroh:2013)

Salah satu media yang dapat digunakan oleh guru yaitu dengan bantuan media musik. Dalam pelaksanaan proses pembelajarannya di SD tidak terlepas dari aktivitas bermusik, walaupun pada umumnya hanya dengan bernyanyi. Aktivitas musik di sekolah dapat mengembangakan keterampilan siswa dalam menguasai bahasa yang dimulai sejak usia dini, bernyanyi adalah salah satu kreativitas musik. Bernyanyi dengan menggunakan lagu-lagu yang dikenal siswa, dan melibatkan musik dalam pelajaran-pelajaran lain akan sangat membantu siswa memahami beberapa mata pelajaran yang dikaitkan dengan satu tema Agar aktivitas pembelajaran tematik di SD mencapai tujuannya sesuai dengan kemampuan perkembangan anak (Azimah :2018). Salah satu media musikny

Secara bentuk kata Seni musik berasal dari dua kata, yaitu "seni” dan "musik". Seni adalah hasil cipta, rasa, dan karsa manusia yang diwujudkan dalam berbagai sarana. Sedangkan musik adalah hasil pengolahan suara, melodi, harmoni, ritme, vokal, dan tempo. Jadi, secara harfiah seni musik adalah hasil cipta, rasa, dan karsa manusia yang diwujudkan dalam olahan suara, melodi, harmoni, ritme, vokal, dan tempo. (Ridwan : 2016)

penggunaan lagu dalam pembelajaran tematik menunjukkan bahwa pada pembelajaran tematik guru menggunakan lagu yang disesuaikan dengan materi ajar yang disampaikan pada pembelajaran tematik. Untuk melengkapi 
penelitian diatas, Linggasari (2017) yang pengkaji kreativitas guru dalam pembelajaran seni musik menunjukan bahwa guru kreatif emilih metode dalam pembelajaran melalui tahap kreativitas: Pendorong, proses, produk. Berdasarkan penelitian tersebut, persoalan kreativitas dalam pembelajaran tematik masih perlu dilakukan (Azimah : 2018)

\section{METODE PENELITIAN}

Metode yang digunakan dalam penulisan artikel ini adalah Literature review atau tinjauan pustaka. Yang digunakan untuk memahami suatu konsep yaitu penggunaan media lagu dalam pembelajaran tematik. Dengan membaca dan mengevaluasi penelitian-penelitian sebelumnya mengenai manfaat musik dalam perkembangan belajar siswa sekolah dasar. Membahas dengan menggunakan teori yang relevan untuk menjelaskan suatu konsep atau gambaran yang dibangun dengan menggeneralisasi suatu pengertian. Sebagai generalisasi, teori memberikan rangkuman terhadap generalisasi empirik dan antar hubungan dari berbagai proposisi yang didasarkan pada asumsi-asumsi tertentu baik yang akan diuji maupun yang telah diterima.

\section{HASIL DAN PEMBAHASAN PENELITIAN}

Harmer (2007a) mengemukakan bahwa karakteristik anak-anak ketika belajar ialah mereka tidak hanya fokus pada apa yang diajarkan, tetapi juga belajar banyak hal pada saat yang bersamaan, seperti mengambil informasi dari sekitarnya. Melihat, mendengar, dan menyentuh sama pentingnya sdengan penjelasan guru dalam proses pemahaman. Abstraksi aturan-aturan gramatika kurang efektif bila diajarkan pada anak-anak. Anak-anak biasanya merespon dengan baik pada aktivitas-aktivitas yang memfokuskan pada kehidupan dan pengalaman mereka. Namun, perhatian anak anak, yaitu kemauan untuk tetap memperhatikan satu kegiatan biasanya singkat. Salah satu karakteristik penting anak-anak adalah kemampuannya menjadi pembicara yang kompeten dari sebuah bahasa baru bila disediakan fasilitas yang memadai, dan bila mendapatkan pajanan bahasa yang mencukupi. (Ratminingsih). Salah satu media yang dapat digunakan guru untuk menyesuaikan karakteristik anak anak sekolah yaitu dengan menggunakan media lagu.

lagu adalah suatu kombinasi musik yang terdiri dari melodi dan lirik atau sebuah komposisi kata dan musik, yang memiliki harmoni, irama, dan bit serta memiliki struktur yang berupa pengulangan-pengulangan syair dan korus, yang bisa diiringi dengan instrumen musik atau tanpa instrumen. (Ratminingsih).

Menurut Sudjana dalam Meliyani (2009:22) Kelebihan media lagu adalah dapat diputar berulang kali sesuai dengan kebutuhan siswa, mengembangkan daya imajinasi siswa, sangat efektif untuk pembelajaran bahasa dan pengadaan programnya sangat mudah.(Zulfa bakar)

Kreativitas guru dalam menggunakan lagu dapat dilihat pada proses pembelajaran dari kegiatan pembuka, kegiatan inti, dan kegiatan penutup pada pembelajaran. Guru kelas I dan V menggunakan yel-yel pada saat kegiatan pembuka untuk menarik perhatian siswa seperti yang dikatakan Rosdiati (2014:103) guru dituntut untuk bisa membuat suasana didalam kelas dapat menimbulkan perhatian siswa agar terpacu pada pembelajaran. (Azimah : 2018)

Lagu pada pembelajaran tematik berpengaruh terhadap minat belajar siswa. Dengan bernyanyi siswa akan merasa senang, tenang dan damai. dengan berlagu siswa akan dapat dengan mudak mengekspresikan suasana hatinya. Siswa juga dapat mengungkapkan melalui kata-kata maupun dengan gerakan. Dengan lagu yang disampaikan memiliki pesan yang terkandung dalam lirinya mengenai konsep pembelajaran. 
Bahasa yang sederhana pada lagu yang diberikan siswa akan lebih mudah memahami dan mengingat pelajaran. Keteratikan minat belajar siswa pada pembelajaran tematik merupakan factor internal siswa dalam keberhasilan belajar siswa, selain kecerdasan, bakat, motivasi dan emosi siswa (Wardani, 2010).

Hal ini sejalan dengan penelitian Herawati (2015) yang berjudul Efektifitas penggunaan lagu model terhadap kemampuan menghafal siswa kelas I pada pembelajaran tematik. didapatkan bahwa hasil posstest pada kelas control adalah 62 dan kelas eksperimen adalah 71,67 yang mana thitungnya 3,81 yang menunjukkan lebih besar dari ttabel. Kesimpulan dari penelitian ini membuktikan efektifitas penggunaan lagu terhadap kemampuan menghafal siswa kelas I sekolah dasar.

\section{KESIMPULAN}

Lagu dapat digunakan guru untuk sebagai media dalam pembelajaran tematik. Dengan lagu siswa dapat memahami dengan mudah tentang pelajaran yang di berikan oleh guru. Sehingga pada saat siswa mengerti dan pahaman dengan pembelajaran yang di berikan oleh guru sehingga dapat eningkatkan hasil belajar siswa dan tujuan pembelajaran pun tercapai.

\section{DAFTAR PUSTAKA}

Abdul Kadir Dan Hanun Asrohah. 2014. Pembelajaran Tematik. Jakarta: PT Raja Grafindo Persada

Dwi, Herawati (2015) Efektivitas Penggunaan Lagu Model Terhadap Kemampuan Menghafal Siswa Kelas I Pada Pembelajaran Tematik.

Linggasari, Aesijah, Raharjo KREATIVITAS GURU DALAM PEMBELAJARAN MUSIK DI TAMAN KANAK-KANAK (TK) KEMALA BHAYANGAKARI 62 BOYOLALI JURNAL SENI MUSIK 6 (2) (2017)
Maghfiroh, Lailatul. Penggunaan Media Flashcard Untuk Meningkatkan Hasil Belajar Ips Pada Pembelajaan Tematik Di Sekolah Dasar.

Nur, Azimah, Udi Utomo Kreativitas Guru Dalam Menggunakan Lagu-Lagu Pada Pembelajaran Tematik Di Sekolah Dasar. JURNAL SENI MUSIK 7(1) 2018

Wardani, D. A., (2010) Analisis Lagu Anak Terhadap Minat Belajar Siswa Dalam Pembelajaran Tematik Kelas 2 Sdn 2 Banyuurip Kecamatan Kalidawir Kabupaten Tulungagung.

Zulfa Bakar, PEMANFAATAN LAGU SEBAGAI IMPLEMENTASI MODEL PAKEM PADA JENJANG PENDIDIKAN ANAK USIA DINI DAN SEKOLAH DASAR 